\title{
Multivariate stimulus processing by normal and paranoid schizophrenic subjects
}

MARCIA GRODIN AND DONALD R. BROWH

PURDUE UNIVERSITY

The adequacy of a linear model was evaluated in a multivariate perceptual context by using multiple regression procedures to predict the judgment "friendly-unfriendly" from facial characteristics of line-drawings and to determine whether the equations were reliably related to the subject classification normal us paranoid schizophrenic. Normal Ss performed in a consistent linear fashion more often than did the schizophrenic $S$ s, but prediction equations were subjectspecific.

Rodwan \& Hake (1964) have recently utilized the linear discriminant function (LDF) as a procedure for quantifying perceptual judgments in response to multivariate stimulation. In a series of studies involving schematized human faces as stimuli, they were able to demonstrate that simple judgments were a reliable linear function of facial characteristics. Previous research using schematic faces (Samuels, 1939), stick-figure drawings (Sarbin \& Hardyck, 1955), and photographs (Izard, 1959; Narrol, 1962) have reported consistent differences between the perceptual judgments of normals and paranoid schizophrenics. However, no attempt has been made to quantitatively express the nature of such differences.

If reliable perceptual differences exist between normals and paranoids, it does not seem unreasonable to assume that differential cue utilization should occur when individuals from these groups are compared in a multivariate perceptual task. The present study was an attempt to subject this assumption to experimental test.

Stimuli

The stimulus objects were the 81 slides of schematic faces used by Rodwan \& Hake (1964). Each face varied along four dimensions: length of nose, $x_{1}$; length of chin, $x_{2}$; distance between the nasal edges of the eyes, $\mathrm{x}_{3}$; and helght of forehead, $\mathrm{x}_{4}$. There were three values of each of the dimensions, and every possible permutation appeared in one slide.

Method

Thirty-two hospitalized paranold schizophrenics (P) and 32 nonhospitalized (N) adult males served as Ss. Hospitalized Ss were selected with a diagnosis of paranoid schizophrenia, not more than five years of hospitalization, and were all reported to be actively delusional or hallucinatory prior to their last admission. Normal Ss were selected from among blue collar and lower echelon white collar employees of the same Veterans Administration Hospital from which patients were selected.
The 81 slides were divided into two groups of 40 and 41 each and were presented to $\mathrm{Ss}$ in two sessions with half of each group receiving them in the A-B order and half in the B-A order. Slides were presented in an independent random order for each $S$ within each set. Using a random-access projector. slides were projected at a distance of $15 \mathrm{ft}$ in individual sessions in a dimly lighted room. Ss were instructed to make a judgment of friendly or unfriendly based upon their immediate impression of each slide. Testing was preceded by practice on six sample faces. Results and Discussion

Analyses were directed toward determining whether individual S's judgments were a reliable linear function of facial characteristics, and whether group membership was related to the use of stimulus dimensions.

Multiple linear regression equations were used to predict judgments from the best linear combination of facial characteristics for each $S$. The least squares weights assigned to cues which maximize the square of the correlation between predicted and observed judgments are proportional to those obtained with the LDF. The equations may, therefore, be compared to those obtained in studies using the LDF. ${ }^{1}$ When regression equations were computed for each of the $64 \mathrm{Ss}$, the analysis yielded 23 equations for which prediction was at an above-chance level ( $\leq \leq .05)$, 1.e., the multiple correlation was greater than zero. These equations are summarized in Table 1. Of the $23 \mathrm{Ss}$ who used cues in a consistent linear fashion, 16 were from the sample of 32 normal Ss, while only seven were from among the schizophrenic Ss. A chi-square statistic was used to test the hypothesis that the frequency of occurrence of conslstent performance was randomly related to normal $\nabla s$ schizophrenic group membership, and was rejected $\left(X^{2}=5.49\right.$, df $=1, \mathrm{p} \leq .05$ ).

As a second method of examining the relation between consistency of cue utilization and experimental conditions, an analysis of variance was computed using the square of the multiple correlation as the dependent variable for each $\mathrm{S}$. The square of the multiple correlation represents the proportion of varlance in judgments which is predictable from a linear combination of cues. Therefore, this analysis tests whether the degree of linear relation between cues and judgments varied for the two groups. The dependent variable was transformed to arcsines to meet the analysis of variance assumptions, and the 
Table 1. Standard Score Regression Weights of Significant Regression Equations for Individual Ss

\begin{tabular}{|c|c|c|c|c|c|c|}
\hline$S$ & & Group & $x_{1}$ & $x_{2}$ & $x_{3}$ & $x_{4}$ \\
\hline 2 & $\star \star$ & $P$ & -31 & -.09 & .09 & .11 \\
\hline 6 & $\star \star$ & $P$ & -.15 & .33 & .02 & .04 \\
\hline 9 & $\star$ & $P$ & -.15 & - & .07 & .06 \\
\hline 12 & * & $P$ & .09 & .09 & .06 & .04 \\
\hline 16 & * & $P$ & -.07 & .20 & -.09 & .04 \\
\hline 25 & $\star \star$ & $P$ & .07 & .11 & .06 & .20 \\
\hline 29 & $* *$ & $P$ & .02 & .17 & .15 & -.07 \\
\hline 33 & $\star \star$ & $\mathbf{N}$ & .09 & .02 & -.24 & .20 \\
\hline 36 & $\star \star$ & $N$ & -.04 & .31 & .02 & -.02 \\
\hline 40 & $\star *$ & $N$ & .00 & .28 & .06 & .07 \\
\hline 43 & $\star \star$ & $N$ & -.15 & -.20 & -.09 & -.07 \\
\hline 46 & $\star \star$ & $\mathrm{N}$ & -.15 & .19 & -.09 & .05 \\
\hline 47 & $\star \star$ & $N$ & .00 & .19 & .22 & -.13 \\
\hline 49 & $\star$ & $N$ & .02 & .20 & .00 & .06 \\
\hline 50 & $\star \star$ & $N$ & -.22 & .11 & .00 & -.02 \\
\hline 52 & * & $N$ & .02 & .22 & -.06 & .06 \\
\hline 53 & $\star \star$ & $N$ & -.28 & -.13 & -.02 & -.15 \\
\hline 54 & $\star \star$ & $N$ & -.31 & -.06 & -.06 & -.06 \\
\hline 57 & $\star \star$ & $\mathrm{N}$ & -.11 & -.07 & -.24 & -.06 \\
\hline 58 & $\star \star$ & $N$ & .11 & .37 & .07 & .13 \\
\hline 59 & $\star \star$ & $N$ & -.09 & .11 & -.11 & -.02 \\
\hline 60 & $\star \star$ & $N$ & .09 & .00 & .17 & .20 \\
\hline 62 & $\star \star$ & $N$ & -.06 & .31 & .02 & .07 \\
\hline$\star$ & le & & icant & & & \\
\hline
\end{tabular}

significant main effect ( $F=4.44, d f=1 / 62, p \leq .05$ ) for groups clearly supports the data outlined in Table 1; normal Ss performed in a reliable linear fashion to an extent which exceeded that for paranoid Ss.

As a final consideration, it would be desirable to examine the nature of the linear function which relates cues to judgments to determine the extent to which group membership influences the kind of stimulus information utilized. When the equations summarized in Table 1 are examined, however, no such pattern arises. While there does appear to be some preference for judging friendliness based upon chin length, inter-S consistency is limited and this does not appear to be systematically related to group membership. The results support the conclusion that normal Ss are more likely to respond in a consistent, linear fashion than are paranoid schizophrenic Ss in this simple, multiple-cue task. They do not, however, support the idea that the nature of the linear cuewelghting function can be used to distinguish group membership. Where reliable linear performance was observed, the nature of the equation was largely subject-specific.

Rodwan \& Hake (1964) report that the responses of normal Ss (students) to these stimuli could be closely fit with the LDF when the judgment dichotomy was "intelligent-not intelligent." They also concluded that discriminant weights were similar among Ss and highly reliable over time. The present data are not consistent with these conclusions. It may be that college students have more stable perceptual systems with greater communality for judging intelligence than the types of Ss used herein have for judging friendliness. If not, the adequacy of the LDF as a model for perceptual function requires further investigation.

\section{References}

Hursch, C. J., Hammond, K. R., \& Hursch, J. L. Some methodological considerations in multiple-cue probability studies. Psychol. Rev., 1964, 71, 42-60.

Izard, C. E. Paranoid schizophrenic's and normal subject's perceptions of photographs of human faces. J. consult. Psychol., $1959,23,119-124$.

Narrol, H. G. Anchor effects on the social perception of medical and schizophrenic hospital patients. Unpublished doctoral dissertation, Indiana University, 1962.

Rodwan, A. S., \& Hake, H. W. The discriminant function as a model for perception. Amer. J. Psychol., 1964, 26, 380-392.

Samuels, Myra, R. Judgments of faces. Charact. \& Pers., 1939, 8, 18-27.

Sarbin, T. R., \& Hardyck, C. C. Conformance in role perception as a personality variable. J. consult. Psychol., 1955, 19, 109-111.

\section{Note}

1. This is true when a set of continuous predictors are related to a dichotomous criterion. The appropriate linear correlations are point-biserial correlations between predictors and criterion. This procedure was used herein since the square of the multiple correlation provides a convenient measure of goodness of fit of the linear model to performance. 